\title{
Erratum to: Outcome for stage II and III rectal and colon cancer equally good after treatment improvement over three decades
}

\author{
Joern Fischer ${ }^{1}$ - Gunter Hellmich ${ }^{1}$ - Thomas Jackisch ${ }^{1}$ - Erik Puffer ${ }^{2}$. Jörg Zimmer ${ }^{3}$. \\ Dorothea Bleyl $^{4}$ - Thomas Kittner ${ }^{5}$ - Helmut Witzigmann ${ }^{1}$ - Sigmar Stelzner ${ }^{1,6}$
}

Published online: 13 February 2016

(C) Springer-Verlag Berlin Heidelberg 2016

Erratum to: Int J Colorectal Dis (2015) 30:797-806

DOI 10.1007/s00384-015-2219-5

The original version of this article unfortunately contains an error in the name of the authors. The first and family names were interchanged. The correct author names are now presented in the authorgroup.

The online version of the original article can be found at http://dx.doi.org/ 10.1007/s00384-015-2219-5.

Sigmar Stelzner

stelzner-si@KHDF.de

1 Department of General and Visceral Surgery, Dresden-Friedrichstadt General Hospital, Teaching Hospital of the Technical University of Dresden, Dresden, Germany

2 Institute of Pathology, Dresden-Friedrichstadt General Hospital, Teaching Hospital of the Technical University of Dresden, Dresden, Germany

3 Department of Radiation Therapy, Dresden-Friedrichstadt General Hospital, Teaching Hospital of the Technical University of Dresden, Dresden, Germany
4 Department of Oncology, Dresden-Friedrichstadt General Hospital, Teaching Hospital of the Technical University of Dresden, Dresden, Germany

5 Department of Radiology, Dresden-Friedrichstadt General Hospital, Teaching Hospital of the Technical University of Dresden, Dresden, Germany

6 Klinik für Allgemein- und Viszeralchirurgie, Krankenhaus Dresden-Friedrichstadt, Friedrichstraße 41, 01067 Dresden, Germany 